\title{
UMA ANÁLISE CRÍTICA ACERCA DA UNIVERSALIZAÇÃO DOS DIREITOS HUMANOS FRENTE AO SEU RELATIVISMO SISTÊMICO: UMA REALIDADE ALÉM DA HERMENÊUTICA
}

\section{A CRITICAL ANALYSIS OF THE UNIVERSALIZATION OF HUMAN RIGHTS IN THE FACE OF SYSTEMIC RELATIVISM: A REALITY BEYOND HERMENEUTICS}

\author{
Hamilton da Cunha Iribure Júnior ${ }^{1}$ \\ Gustavo Silva Xavier ${ }^{2}$
}

\section{RESUMO}

O presente artigo procede a uma análise dos direitos humanos partindo da constatação de que sua gênese se dá num contexto histórico-cultural específico, e expressam a cosmovisão do seu lugar de nascimento - o mundo ocidental -, com suas ideologias, costumes, valores e crenças. Ramon Panikkar e Boaventura de Sousa Santos, que referenciam esta análise, preconizam a tese de que a universalidade dos direitos humanos somente pode ser alcançada por meio de uma hermenêutica diatópica, que contemple a multiplicidade de culturas existentes em todo o mundo, pois uma hermenêutica que insiste na predominância dos valores das culturas ocidentais não encontra legitimidade perante várias outras culturas, que se sentirão excluídas. O problema que perpassa a pesquisa tem seu fulcro no binômio universalismo/relativismo dos direitos humanos. Justifica-se a pesquisa em razão das formas díspares de compreensão e aplicação dos Diretos Humanos nas várias regiões do mundo, e na importância da superação da antítese universalismo/relativismo no que se refere aos Direitos Humanos. A hermenêutica diatópica e o multiculturalismo emancipatório, ambos valendo-se do diálogo intercultural, configuram-se como um caminho para a construção do diálogo sobre a universalização de direitos e a reconstrução e reconceitualização dos direitos humanos em âmbito global, respeitando as particularidades locais de cada cultura. Para tanto, emprega-se a metodologia investigativa analítico-dedutiva.

Palavras-chave: direitos humanos; universalismo; relativismo; sociedade; multiculturalismo.

\footnotetext{
${ }^{1}$ Doutor em Direito pela Pontifícia Universidade Católica de São Paulo PUC/SP (2009). Mestre em Direito pela Pontifícia Universidade Católica de São Paulo PUC/SP (2005). Especialista em Direito Processual Civil pela Universidade de Cuiabá (2002). Mestre em Engenharia Civil pela Pontifícia Universidade Católica do Rio de Janeiro PUC/Rio (1991). Atualmente é Professor Adjunto da Graduação e do Programa de Mestrado da Faculdade de Direito do Sul de Minas (FDSM). Advogado inscrito na Ordem dos Advogados do Brasil (OAB). Pesquisador CNPq. Faculdade de Direito do Sul de Minas. Minas Gerais. Lattes: http://lattes.cnpq.br/9009611714454221 ORCID: http://orcid.org/0000-0002-0036-3587 E-mail: hamilton.adv@terra.com.br

${ }^{2}$ Mestre em Direito pela Faculdade de Direito do Sul de Minas (FDSM). Professor do curso de Graduação e da Pós-Graduação do Centro Universitário de Itajubá (FEPI). Editor Associado da Revista Eletrônica da Faculdade de Direito do Sul de Minas. Procurador Legislativo da Câmara Municipal de Borda da Mata/MG. Advogado regularmente inscrito na Ordem dos Advogados do Brasil (OAB). Pesquisador CNPq. Centro Universitário de Itajubá (FEPI). Minas Gerais. Lattes: http://lattes.cnpq.br/9488087504267525 ORCID: https://orcid.org/00000002-1304-3523. E-mail: gustavoadv.fdsm@gmail.com
} 


\begin{abstract}
This article analyzes human rights based on the observation that their genesis occurs in a specific historical and cultural context, and that they express the worldview of their birthplace - the Western world - with its ideologies, customs, values and beliefs. Ramon Panikkar and Boaventura de Sousa Santos, who refer to this analysis, advocate the thesis that the universality of human rights can only be achieved through a diatopical hermeneutics, which contemplates the multiplicity of cultures existing in the whole world, because a hermeneutics that insists on the predominance of the values of Western cultures will not find legitimacy before several other cultures, which will feel excluded. The problem that pervades this research is rooted in the universalism/relativism binomial of human rights. The research is justified due to the disparate ways of understanding and applying Human Rights in the various regions of the world, and the importance of overcoming the universalism/relativism antithesis with regard to Human Rights. The diatopical hermeneutics and emancipatory multiculturalism, both making use of intercultural dialogue, are configured as a path for the construction of dialogue on the universalization of rights and the reconstruction and reconceptualization of human rights at a global level, respecting the local particularities of each culture. To this end, the analyticaldeductive investigative methodology is employed.
\end{abstract}

Keywords: human rights; universalism; relativism; society; multiculturalism.

\title{
INTRODUÇÃO
}

A expressão "Direitos Humanos" tem sido usada de forma recorrente como sendo a expressão de valores universais e, quiçá, absolutos. Assim, ao abordar esta temática nos livros de direito o que normalmente se faz é tão somente discorrer sobre a origem histórica dos Direitos Humanos e sua "evolução", destacando as "gerações" ou "dimensões" dos Direitos Humanos sem, contudo, proceder a uma análise crítica destes direitos. Neste sentido pondera Boaventura de Sousa Santos (2014, p. 15) assevera que é necessário indagar se os direitos humanos servem eficazmente à luta dos excluídos, dos explorados e dos discriminados ou se, pelo contrário, a torna mais difícil. Isto é, "será a hegemonia de que goza hoje o discurso dos direitos humanos o resultado de uma vitória histórica ou, pelo contrário, de uma derrota histórica?". A questão posta exige o seu enfrentamento, e tanto Boaventura de Sousa Santos Santos quanto Ramon Panikkar realizam este enfrentamento valendo-se de instrumentais de análise por eles denominados Hermenêutica Diatópica e Multiculturalismo Emancipatório.

No presente artigo pretende-se discutir questões acerca da hermenêutica diatópica na visão dos autores referidos, dentre outras possibilidades de análise e compreensão dos Direitos Humanos em face do multicularismo, orientando-se por um diálogo intercultural. 
Primeiro, considera-se as tensões entre universalismo/relativismo no que se refere aos direitos humanos, segundo procede-se à análise da hermenêutica diatópica e sua perspectiva intercultural na visão de Panikkar, terceiro realiza-se à análise do multiculturalismo emancipatório preconizado por Boaventura de Sousa Santos, e por fim considera-se a convergência destes instrumentos para a reconstrução e reconceitualização dos Direitos Humanos. Considerar-se-á a viabilidade da utilização destes instrumentos para a promoção do diálogo intercultural com vistas à efetivação da universalidade dos Direitos Humanos, e como uma alternativa para conter a ideia de hegemonia ocidental.

Se, por um lado, a concepção hegemônica dos Direitos Humanos é uma expressão da hegemonia ocidental, por outro lado esta percepção por parte das culturas não ocidentais está na raiz da crise entre estas duas modalidades de culturas, fazendo-se necessário, para a transposição do abismo que as separa, a efetivação de um diálogo compreensivo entre estes dois universos culturais, com todas as suas peculiaridades, valores, tradições, formas de organização etc.

Neste sentido, faz-se necessária uma reconstrução epistemológica dos direitos humanos, de forma que sejam a expressão das tradições e dos valores das várias culturas mundiais, e possam, portanto, serem de forma legítima denominados "Direitos Humanos" e adjetivados como universais.

Não se tem a pretensão de esgotar aqui toda a discussão acerca do debate intercultural sobre os direitos humanos, uma vez que a complexidade e alcance do tema vão muito além dos esforços empreendidos em um artigo científico, mas tão-somente tecer algumas considerações sobre o tema na visão de alguns doutrinadores que perfilham esse campo de estudo.

\section{UMA ANÁLISE DA DIMENSÃO EPISTEMOLÓGICA DOS DIREITOS HUMANOS}

Os Direitos Humanos, que exsurgem dos direitos naturais, concebidos como direitos inerentes ao homem, constituem o alicerce sobre o qual se ergueram as Constituições modernas, mormente no que tange aos direitos e garantias fundamentais, tendo como seu epicentro e seu eixo gravitacional a pessoa humana.

Apresentam-se como conquistas históricas movidas pelas lutas sociais e foram incorporados nas declarações de direitos e sucessivamente positivados nas constituições dos Estados, convertendo-se, assim, no âmbito do direito interno, em direitos fundamentais. As lutas e as pressões sociais buscam o reconhecimento da Dignidade Humana. Nesse sentido, Norberto Bobbio afirma que os direitos do homem, 
[...] por mais fundamentais que sejam, são direitos históricos, ou seja, nascidos em certas circunstâncias, caracterizados por lutas em defesa de novas liberdades contra velhos poderes, e nascidos de modo gradual, não todos de uma vez e nem de uma vez por todas $(1992$, p. 5).

É inegável que a construção de qualquer direito esteja sempre lastreada na história de uma determinada cultura, ou seja, são lutas seguidas de reivindicações por novas liberdades e justiça por pessoas que estão sendo oprimidas através de alguma forma de poder.

Nota-se que o primeiro documento em forma de rascunho da Declaração Universal dos Direitos Humanos contou com a participação de mais de 50 países, foi apresentado em setembro de 1946 e teve seu texto final redigido em menos de dois anos, logo, a Declaração Universal dos Direitos Humanos começou a ser discutida quando o mundo sentia os efeitos da Segunda Guerra Mundial.

Tendo a igualdade humana como princípio de direitos, sejam eles civis, políticos, econômicos e sociais, após as desastrosas Primeira e Segunda guerras mundiais, os líderes políticos das grandes potências criaram a Organização das Nações Unidas - ONU - e confiaram-lhe a tarefa de evitar a guerra e de promover a paz entre as nações. Em 1946, a ONU criou o Comitê de Direitos Humanos responsável pela redação da Declaração Universal dos Direitos Humanos.

Com a promulgação da Declaração Universal dos Direitos Humanosll, em 10 de dezembro de 1948, pela ONU, e sendo o Brasil um dos Estados-Membros, se comprometeu a promover o respeito universal aos direitos e liberdades humanas fundamentais e a observância desses direitos e liberdades (COMPARATO, 2015, p. 225).

A Declaração Universal dos Direitos Humanos (DUDH) foi aprovada em 1948 na Assembleia Geral da Organização das Nações Unidas (ONU). O documento é a base da luta universal contra a opressão e a discriminação, defende a igualdade e a dignidade das pessoas e reconhece que os direitos humanos e as liberdades fundamentais devem ser aplicados a cada cidadão do planeta.

Segundo Oliveira (2014) a promulgação da Declaração Universal dos Direitos Humanos pela Assembleia Geral da Organização das Nações Unidas, em Paris, em 1948, três anos após o fim da Segunda Guerra Mundial, foi o marco inicial de uma nova visão no campo dos Direitos Humanos, trazendo um novo cenário para o mundo internacional. Por essa razão, o princípio da soberania absoluta dos Estados foi relativizada e abriu-se margem para o 
princípio genuíno da proteção do ser humano, que passou a ser a questão principal nas relações jurídicas de âmbito nacional e internacional.

Porém, uma questão merece ser discutida: é totalmente correto afirmar a universalidade dos Direitos Humanos, ou estes devem ser considerados em sua relatividade cultural? Como observa Flávia Piovesan (2006, p. 114) “A concepção universal dos direitos humanos demarcada pela Declaração sofreu e sofre, entretanto, fortes resistências dos adeptos do movimento do relativismo cultural". A discussão orienta-se no sentido de verificar o alcance das normas de direitos humanos, ou seja, se elas podem ter um sentido universal ou se são culturalmente relativas.

Sob a ótica dos relativistas a noção de direitos humanos está associada ao sistema político, econômico, cultural, social e moral vigente em uma determinada sociedade, e neste sentido, o pluralismo cultural seria um impeditivo à formação de uma moral universal, exigindo que as diferenças culturais peculiares a cada sociedade sejam respeitadas, como por exemplo, as peculiaridades das culturas hinduísta e islâmica. Com efeito, a compreensão de uma cultura exige que se realize nela uma imersão, logo, tal compreensão somente pode ocorrer numa condição existencial.

Assim sendo, forçoso seria concluir que não há uma moral universal, e todo universalismo moral, como por exemplo, o universalismo kantiano, seria uma expressão imperialista, uma imposição universal de uma moral local. Ocorre que, como observa Piovesan (2006, p. 115), "os instrumentos internacionais de direitos humanos são claramente universalistas, uma vez que buscam assegurar a proteção universal dos direitos e liberdades fundamentais". E as afirmações "todas as pessoas têm direito à vida e à liberdade" - $\operatorname{art.} 2^{\circ}$ da Declaração, "ninguém poderá ser submetido à tortura" - art. $5^{\circ}$ da Declaração, dentre outras, aponta para o seu caráter universal.

Para os relativistas a pretensão de universalidade dos Direitos Humanos indica a arrogância do imperialismo cultural do mundo ocidental, que estaria com isto universalizando suas próprias crenças, e por via de consequência, conduziria à destruição da diversidade cultural.

Por sua vez, os universalistas, como observa Flávia Piovesan (2006, p. 144), reagem "alegando que a posição relativista revela o esforço de justificar graves casos de violações dos direitos humanos que, com base no sofisticado argumento do relativismo cultural, ficariam imunes ao controle da comunidade internacional". 
Apontam, assim, os universalistas, que por trás dos argumentos dos relativistas, o que se encontra é uma enorme resistência por parte de alguns governos e culturas em se submeter às normas dos Direitos Humanos com o fito de continuar praticando atos que seriam considerados violações dos Direitos Humanos. Além disso, objetam os universalistas que "a existência de normas universais pertinentes ao valor dignidade humana constitui exigência do mundo contemporâneo (PIOVESAN, 2006, p. 145)".

Outro argumento utilizado pelos universalistas consiste no fato de que, uma vez que os instrumentos internacionais de proteção dos direitos humanos, foram ratificados pelos Estados signatários destes instrumentos, logo, têm eles o dever político e moral de exercer o controle da comunidade internacional em caso de violação destes direitos, pois tal conduta importa em descumprimento de obrigações internacionais.

Tendo em vista esta questão de fundo decorrente da tensão entre o universalismo e o relativismo concernentes aos direitos humanos, a Declaração e Programa de Ação de Viena, de 25 de junho de 1993 , em seu artigo $5^{\circ}$., assim estabeleceu:

Todos os direitos humanos são universais, indivisíveis, interdependentes e interrelacionados. A comunidade internacional deve tratar os direitos humanos globalmente, de maneira justa e equânime, com os mesmos parâmetros e com a mesma ênfase. As particularidades nacionais e regionais e bases históricas, culturais e religiosas devem ser consideradas, mas é obrigação dos Estados, independentemente de seu sistema político, econômico e cultural, promover e proteger todos os direitos humanos e liberdades fundamentais.

O que a Declaração pretendeu, dentre outras coisas, foi afirmar que não há contradição entre os princípios universais da Declaração da ONU e as diversas culturas existentes na comunidade internacional.

\section{COMPREENDENDO CULTURALMENTE OS DIREITOS HUMANOS}

Não obstante as considerações desenvolvidas no tópico anterior, a grande questão é que os direitos humanos aprovados pela Declaração Universal em 1948 foram lastreados nas raízes ocidentais com pressupostos e implicações do conceito ocidental de homem, valores, direitos e nação. A formação destas concepções remonta à Revolução Francesa, quando o homem ocidental passa de um pertencimento corporativo a uma comunidade de sangue. Nesse sentido Panikkar aponta os pressupostos dos fundamentos da Declaração:

1. Na base do discurso sobre direitos humanos encontra-se o pressuposto de uma natureza humana universal, comum a todos os povos (...) essa ideia, por sua vez, está ligada à antiga noção de lei natural. a) esta natureza humana deva ser cognoscível, pois uma coisa é aceitar a natureza humana de forma acrítica ou 
mítica, e outra coisa, é conhecê-la (...) b) que essa natureza humana seja conhecida por intermédio de um instrumento também universal de conhecimento, geralmente chamado razão. (...)c) que essa natureza humana seja, em sua essência, diferente do resto da realidade. Os outros seres vivos são inferiores ao homem e não têm, obviamente, Direitos Humanos, e é provável que não existam criaturas superiores ao homem.

2. (...) O segundo pressuposto é da dignidade do indivíduo. (...) Eles defendem a dignidade do indivíduo frente à sociedade como um todo e ao estado em particular.

3. (...) O terceiro pressuposto é o da ordem social democrática. Parte do princípio que a sociedade não é uma ordem hierárquica fundada na vontade ou na lei divina, mas sim uma soma de indivíduos "livres", organizado para conquistar objetivos que, caso contrário, não seriam possíveis. (...) Essa sociedade cristaliza-se no Estado que, em termos teóricos, expressa a vontade do povo, ou, pelo menos, da maioria. (...) (PANIKKAR, 2004, p. 212).

Pelos pressupostos mencionados nota-se que a Declaração Universal foi articulada claramente de acordo com as tendências históricas do mundo ocidental, porém estes pressupostos não são reconhecidos universalmente nem de forma unânime no campo da cultura ocidental.

Nesse sentido, trazemos à baila a consideração de Bobbio (2004, p. 53): “Os direitos elencados na Declaração não são os únicos e possíveis direitos do homem: são os direitos do homem histórico, tal como este se configura na mente dos redatores da Declaração após a tragédia da Segunda Guerra Mundial”.

A cultura ocidental, abalada pela barbárie da Segunda Guerra Mundial, e com o intuito de construir um mundo sob novos eixos políticos, buscou se reinventar sobre novas bases. Os dirigentes das nações que surgiram como potências no período pós-guerra, liderados por Estados Unidos e União Soviética, estabeleceram, na Conferência de Yalta, na Criméia, em1945, as bases de uma futura paz mundial, criando áreas de influência das potências e acertando a criação de uma organização multilateral que promovesse negociações sobre conflitos internacionais, para evitar guerras e promover a paz e a democracia, com vistas a fortalecer os Direitos Humanos.

Nos fundamentos dos direitos humanos há a compreensão de que estes são essenciais a todos os seres humanos, sem que haja nenhuma discriminação seja ela qual for. Eles podem ser civis, políticos e sociais, como o direito à vida, à igualdade perante a lei e à liberdade de expressão. A garantia dos direitos humanos universais é construída através da lei, podendo citar como exemplo, os tratados e as leis internacionais, portanto, deve haver diálogo entre as culturas para melhor compreensão dos direitos protegidos. 
Além do mais, como já dito, os direitos humanos são conquistas históricas promovidas por diversas lutas e foram incorporados nas declarações de direitos e posteriormente positivados juridicamente nas constituições dos Estados nacionais, transformando-se, assim, em direitos fundamentais e essenciais ao ser humano.

Nota-se que os direitos humanos têm como eixo a preservação da dignidade humana e que foi a partir da segunda Guerra Mundial, após milhares de mortes envolvendo judeus, soviéticos, europeus etc., que se iniciaram e se fortaleceram os debates sobre a necessidade da criação dos Direitos Humanos Universais.

O que não se pode ignorar é que foi no Ocidente que surgiu a tentativa de universalização dos direitos de acordo com suas próprias ideologias e culturas, e isso leva, muitas vezes, ao exclusivismo e à ideia de localismo, que é a crença de que a sua cultura, suas leis ou ideologias são verdades absolutas e genuínas, o que não pode e não deve prevalecer, pois nenhuma cultura pode por si só determinar a universalização de direito embasada na sua única história. Portanto, para que os direitos humanos sejam universalizados é necessário dialogar sobre os conceitos dos direitos que se pretendem proteger entre as diversas culturas.

Observa-se que a universalização dos direitos humanos criada pelo mundo ocidental visa à aplicação de valores únicos a todos os seres humanos, tomando o modelo ocidental como ponto de partida. Os direitos humanos têm como critério um conjunto de pressupostos, todos eles tipicamente ocidentais. Além disso, a Declaração Universal de 1948 foi elaborada sem a participação da maioria dos povos do mundo, restringindo a participação dos povos dominados, subjugados pelo colonialismo europeu (BOAVENTURA, 2004, p. 266).

Observe-se, a título de exemplo, que a África do Sul somente foi verdadeiramente livre do jugo britânico em 1993 com a eleição de Nelson Mandela, e isto quase 50 anos após a publicação da Declaração Universal de Direitos Humanos. Assim, tais pressupostos são fundados em uma disputa pela hegemonia no plano internacional, e são consagrados inicialmente no texto da Declaração Universal dos Direitos Humanos em 1948.

Assim, é imprescindível que os direitos humanos tornem-se uma universalidade, e sejam erguidos de baixo para cima, de forma cosmopolita, ao contrário da universalidade da atualidade, com base no imperialismo ocidental.

Panikkar (2004) apresenta um possível caminho, ou um ponto de partida para a universalidade fática dos direitos humanos através da hermenêutica diatópica, que propõe o diálogo intercultural sobre preocupações isomórficas, ou seja, a busca por conceitos similares entre as culturas, à medida em que o debate pelos direitos humanos pode evoluir para o diálogo 
opositor entre as culturas sobre os princípios de dignidade humana, sem prevalecer assim, a ideia de imposição de hegemonia de nenhuma cultura, mas a troca de conhecimento que possa de fato se completar umas as outras. A dialógica intercultural se coloca como caminho necessário à construção de direitos humanos sob uma perspectiva de horizontalidade e alteridade, no contexto de um mundo multicultural e plural.

Pannikar foi o precursor da discussão intercultural contemporânea no campo dos direitos humanos. Porém, antes de adentrar na questão da hermenêutica diatópica proposta pelo autor, importante destacar um pouco sobre a vida do autor, pois é notório que o estudo da hermenêutica diatópica desencadeou-se a partir da sua própria história de vida.

Panikkar é filho de pai indiano e da religião hindu e mãe catalã católica romana. Foi educado no colégio dos padres mesmo sendo filho de um Indiano. Estudou filosofia na Índia e engajou-se então em um diálogo hindu-cristão, e assim surgiu a ideia da hermenêutica diatópica. Destaca-se, porém, que o estudo feito por ele visa inicialmente à análise de relações “intra-religiosas", e não do diálogo intercultural, inspirado pela própria vivencia familiar e, que foi amplamente usado para a construção deste tema. Panikkar apresenta a teoria da "hermenêutica diatópica" como condição para que o diálogo intercultural seja possível.

Sobre a "hermenêutica diatópica", Panikkar (2004, p. 205) ensina que o método da interculturalidade não poderá interpretar ou comparar textos, já que seria uma interpretação baseada em contextos. Assim, a expressão "hermenêutica diatópica" aponta para uma tarefa interpretativa em diálogo com seres humanos de outra cultura.

Para Panikkar (2004) "hermenêutica" é uma palavra que expressa uma noção de interpretação, sendo que tal termo provém do verbo grego hermeneuein, que significa declarar, enunciar, interpretar, ou esclarecer. A palavra "diatópica", por sua vez, é a conjunção de duas palavras gregas: dia, que significa através e topos, que pode ser traduzida como lugar cultural comum. Assim, a expressão "hermenêutica diatópica" carrega a noção de uma interpretação feita através de um lugar cultural comum.

Para a interpretação de qualquer conteúdo, dever-se-á, segundo o autor, estudar a razão daquele, e não a ótica de quem o interpreta. A opção do termo "hermenêutica diatópica" para tal interpretação intercultural deu-se por conta do significado da palavra diatópico, que, como já foi mencionado, deriva do grego dia e topos, que seria através de e lugar cultural ou o já conhecido topoi. 


\begin{abstract}
A fundação de uma cultura não precisava ser a de outra, pois, nesse caso, os significados não são transferíveis... Assim sendo, o que devemos fazer? Devemos cavar até encontrar um solo homogêneo ou uma problemática semelhante; devemos buscar o equivalente homeomórfico - neste caso, o conceito de Direitos Humanos... Homeomorfismo não é o mesmo que analogia; ele representa um equivalente funcional específico, descoberto através de uma transformação topológica. É um tipo de analogia funcional existencial PANIKKAR, 2004, p. 209).
\end{abstract}

A hermenêutica diatópica se fundamenta na ideia de que os topoi de uma cultura nunca são completos, e que uma cultura depende da outra para se completar, não se tratando de imposição por parte de nenhuma cultura. Logo, a incompletude de uma dada cultura poderá ser complementada com os topoi de outra cultura através do diálogo intercultural, que significa reciprocidade ou solidariedade, respeitando o outro como ele é e não sob a ótica do Poder e da imposição de padrões e valores culturais de superioridade, mas no mesmo nível hierárquico de aprendizagem dialogada.

Vale destacar alguns dados importantes da visão indiana para a questão em discussão e para o diálogo intercultural: $\mathrm{Na}$ índia os direitos humanos não são apenas individuais, os animais também tem direitos, e num sentido muito mais amplo que no ocidente, tendo em vista que muitos deles são considerados divindades que sobrevivem e acompanham a história milenar nesta jornada. Assim para os indianos, a questão dos direitos humanos tratarem somente o ser humano como sujeito de direito já é uma questão de rejeição.

O logos cartesiano e kantiano (razão) não explica por si só os direitos humanos, a linguagem dos mitos e as outras narrativas devem ser objetos de aprendizagem. Neste sentido, a pesquisa realizada por Gustav Jung sobre os arquétipos precisaria ser mais valorizada no campo de estudos no ocidente, tendo em vista o valor que confere aos mitos. E é interessante que Jung dedicou-se ao estudo e à aproximação do pensamento ocidental com o oriental, tendo estudado a cultura hindu, a filosofia da yoga, dentre outras. Nesse aspecto, Panikkar afirma a necessidade de uma nova hermenêutica:

Resumindo, precisamos de uma nova hermenêutica: a hermenêutica diatópica que só pode ser desenvolvida em um diálogo intercultural. Ela nos mostraria que não podemos tomar a pars pro toto, nem crer que vemos o totum in parte. Devemos aceitar o que o nosso parceiro nos diz: simplesmente, que tomamos o totum pro parte, quando estamos cientes da pars pro toto, o qual é, com certeza, o que lhe responderemos sem vacilar. É a condição humana e eu não a consideraria como uma imperfeição; mais uma vez este é o tema do pluralismo (1996, p. 134). 
Nota-se que a grande missão da universalidade dos direitos humanos é definir o conceito de dignidade humana universal, utilizando o mecanismo do diálogo intercultural, e para concretizar a universalidade há necessidade do diálogo e compreensão entre as diferenças e as incompletudes entre as culturas.

Conclui-se que Panikkar apresenta a "hermenêutica diatópica" como condição para o diálogo intercultural, com vista a tornar-se genuína a universalidade dos direitos humanos, que atualmente são ocidentais disfarçados de universais. A hermenêutica diatópica proposta por Panikkar tem sido considerada por Boaventura de Sousa Santos, cujo pensamento, no que concerne à discussão aqui desenvolvida, será considerado no próximo tópico.

\section{A POSSIBILIDADE DE RECONSTRUIR O ALCANCE DOS DIREITOS HUMANOS}

Boaventura de Sousa Santos é outro pesquisador que tem se dedicado a enfrentar a questão do universalismo e relativismo dos direitos humanos, e sua contribuição tem sido significativa para este debate. Para ele (2004, p. 250) "ainda que todas as culturas tendam a definir os seus valores mais importantes como os mais abrangentes, apenas a cultura ocidental tende a formulá-los como universais".

Por outro lado, para Santos (2004, p. 251), os direitos humanos, que se pretendem universais, não são universais na sua aplicação. E ele aponta que atualmente são consensualmente identificados quatro regimes internacionais de aplicação de direitos humanos: o europeu, o interamericano, o africano e o asiático.

Entendemos que realmente, no que tange à sua aplicação, os direitos humanos têm tratamento diferente, e não só isto, parece-nos que a forma como o mundo ocidental percebe o mundo não ocidental também é diferente, especialmente a forma de percepção presente no norte desenvolvido como Europa e América do Norte. A sensação que se tem é que a vida das pessoas que vivem nestas regiões é mais valiosa que a vida das pessoas que vivem nas demais regiões do globo.

Quando se trata de um atentado terrorista em Paris ou nos Estados Unidos, tal fato é lembrado pela mídia por anos a fio, e celebrações são realizadas para relembrar o ocorrido. Quando o mesmo acontece no Afeganistão, Iraque, Egito, Sudão, Quênia, tal fato é noticiado em um dia e no outro dia já se torna esquecido. O mesmo se percebe na atualidade no que diz respeito à crise de refugiados. 
Boaventura de Sousa Santos (2010, p. 441) coloca a seguinte proposta de superação do universalismo x relativismo dos direitos humanos:

\begin{abstract}
A minha tese é que, os direitos humanos tenderão a operar como localismo globalizado e, portanto, como uma forma de globalização hegemônica. Para poderem operar como forma de cosmopolitismo insurgente, como globalização contra-hegemônica, os direitos humanos têm de ser reconceptualizados como interculturais. Concebidos como direitos universais, como tem sucedido, os direitos humanos tenderão sempre a ser um instrumento do "choque de civilizações" tal como o concebe Samuel Hintington (1993-1997), ou seja como arma do Ocidente contra o resto do mundo ("the West against the rest"), como cosmopolitismo do Ocidente imperial prevalecendo contra quaisquer concepções alternativas de dignidade humana. Por esta via a sua abrangência global será obtida à custa da sua legitimidade local. Pelo contrário, o multiculturalismo emancipatório, tal como eu o entendo e especificarei adiante, é pré-condição de uma relação equilibrada e mutuamente potenciadora entre a competência global e a legitimidade local, os dois atributos de uma política contra-hegemônica de direitos humanos no nosso tempo.
\end{abstract}

Na visão de Santos (2004, p. 447), a hermenêutica diatópica preconizada por Panikkar consiste na aceitação da ideia de que os Direitos Humanos, quando analisados em sua pretensão de universalidade, encontram resistência nas diferenças culturais entre os povos. Por conseguinte, a divergência entre culturas representa, sim, uma dificuldade para a universalização dos Direitos Humanos tal qual concebemos a partir da Declaração da ONU de 1948

Para Santos as culturas possuem suas incompletudes, portanto, se é a consciência da incompletude que dá o primeiro impulso para o diálogo, é a partir deste e da hermenêutica diatópica que as culturas passam a refletir e ponderar sobre suas construções e a reconhecer as construções de outras culturas.

A distinção entre o secular e o religioso assume contornos muito específicos e vinculados na cultura ocidental e, de tal modo, que o que essa distinção distingue, quando aplicada no interior da cultura ocidental, não é equivalente ao que distingue quando aplicada no interior de uma cultura não ocidental. Além disto, observa Sousa Santos que nem mesmo no ocidente a secularização foi alguma vez plenamente atingida, sendo que o que se afirma como secular é o produto de um consenso, em regra obtido democraticamente, sobre o âmbito dos compromissos com exigências religiosas.

Para Boaventura (2014, p. 36), o secularismo é oriundo do paradigma cultural e político da modernidade ocidental:

Depois de séculos de conflitos na Europa, este paradigma alcançou uma resolução sem precedentes da questão religiosa, a questão do papel da religião na sociedade: por um lado, os valores do Cristianismo foram reconhecidos como "universais"; 
e, por outro, o Cristianismo institucional foi relegado para o governo da esfera privada, a esfera das decisões autônomas e voluntárias dos indivíduos. Essa resolução ocidental da questão religiosa tem vindo a ser questionada em muitas partes do mundo, incluindo o mundo ocidental, e traduz-se na reivindicação do papel da religião na vida pública”.

Para Santos (2014) a resolução ocidental moderna da questão religiosa é um localismo globalizado, ou seja, uma solução local que, por via do poder econômico, político e cultural de quem a promove, expande o seu âmbito a todo o globo".

Não sem razão, há forte resistência no que se refere ao discurso dos Direitos Humanos no universo muçulmano, tendo em vista que os Direitos Humanos, com sua matriz secular reverberam para este universo como um antípoda de seus valores, de sua cultura, fortemente arraigada em valores e concepções de vida religiosa. Neste sentido, como observa Santos, as correntes mais radicais do Islã percebem os Direitos Humanos como expressão do paradigma cultural e político ocidental, rejeitando-o na sua totalidade, sem se abrir para a possibilidade de um diálogo, diferente das correntes teológicas mais progressistas existentes no Islã, com as quais se é possível estabelecer diálogos, tendo em vista alguns pontos de convergência, como por exemplo, no que se refere à emancipação feminina.

No que se refere ao islamismo e sua vertente fundamentalista, entretanto, a compreensão é a expressa por Boaventura 2014, p. 96):

\begin{abstract}
A religião deve ser onipresente e permear todas as dimensões da vida por igual. Este entendimento da religião, que é consensual no Islã, é convertido pelo islamismo político fundamentalista na arma política mais decisiva. Por outras palavras, a religião é convertida em arma política contra todos os vestígios de secularização deixados pelos projetos de modernização do nacionalismo árabe considerados fracassados. Daí, o ataque frontal ao Estado laico, à separação entre espaço público e espaço privado e a todas as instituições que se pretendem regidas por normas estranhas à shari'a.
\end{abstract}

Portanto, uma reconstrução dos Direitos Humanos deveria levar em conta o diálogo intercultural, e buscar construir um conjunto de Direitos Humanos que contemple as várias culturas e seus valores.

A concepção dos direitos humanos proposta por Boaventura de Sousa Santos parte da constatação de que os direitos humanos não constituem um princípio universal, tendo em vista que o modelo atual dos direitos humanos encontra-se inserido num contexto de política de expansão, domínio territorial e imperialismo cultural. A grande questão é que nem todas as tradições culturais participaram da elaboração dos instrumentos internacionais de direitos humanos e nem todas as culturas não ocidentais foram inseridas no diálogo. 
Além disso, é através dos fundamentos de universalismo, e por meio da globalização hegemônica, que os valores ocidentais se acobertam de universais, de forma a permitir a propagação de ideias umbilicalmente ligadas ao liberalismo, individualismo e mercado ocidental.

Para o autor, a falácia em torno da universalidade atribuída aos direitos humanos no cenário imperial da globalização hegemônica deve modificar-se numa nova universalidade, construída de baixo para cima: o cosmopolitismo. Sousa Santos não nega os esforços para universalizar um conjunto de valores que possa ser compartilhado por todas as culturas, sejam ocidentais ou não ocidentais. Contudo, alerta:

Enquanto forem concebidos como direitos humanos universais, os direitos humanos tenderão a operar como localismo globalizado e, portanto, como uma forma de globalização hegemônica. Para poderem operar como forma de cosmopolitismo, como globalização contra-hegemônica, os direitos humanos têm de ser reconceitualizados como multiculturais (SANTOS, 2010, p. 96).

Nesse particular, se o que se pretende é o diálogo intercultural sobre a universalidade dos Direitos Humanos entre as diversas culturas do mundo, os discursos culturais necessitam de uma recolocação de modo a atingir as realidades de cada cultura, de maneira a se tornarem mutuamente inteligíveis.

O autor propõe através do diálogo intercultural a busca da construção de uma concepção de direitos humanos que possa ser compartilhada com as diferentes culturas. Portanto, sem uma compreensão profunda da história, das culturas e das civilizações e povos do mundo, é impossível que haja avanço na questão de diálogo sobre a universalidade dos direitos humanos.

Santos elenca algumas premissas a serem seguidas para alcançar o diálogo intercultural com vistas à transformação dos direitos humanos num projeto cosmopolita insurgente:

1.A primeira premissa é a superação do debate sobre universalismo e relativismo cultural. Trata-se de um debate intrinsecamente falso, cujos conceitos polares são igualmente prejudiciais para uma concepção emanciparória de direitos humanos. (...) 2. A segunda premissa da transformação cosmopolita dos direitos humanos é que todas as culturas possuem concepções de dignidade humana, mas nem todas elas a concebem em termos de direitos humanos. Torna-se, por isso, importante identificar preocupações isomórficas entre diferentes culturas. Designações, conceitos e Weltanschaungen diferentes podem transmitir preocupações ou aspirações semelhantes ou mutuamente inteligíveis.

3. A terceira premissa é que todas as culturas são incompletas e problemáticas nas suas concepções de dignidade humana. A incompletude provém da própria existência de uma pluralidade de culturas, pois, se cada cultura fosse tão completa como se julga, existiria apenas uma só cultura. [...] Aumentar a consciência de 
incompletude cultural até ao seu máximo possível é uma das tarefas mais cruciais para a construção de uma concepção multicultural de direitos humanos.

4. A quarta premissa é que nenhuma cultura é monolítica. Todas as culturas comportam versões diferentes de dignidade humana, algumas mais amplas do que outras, algumas com um círculo de reciprocidade mais largo do que outras, algumas mais abertas a outras culturas do que outras.

(...) 5. A quinta premissa é que todas as culturas tendem a distribuir as pessoas e os grupos sociais entre dois princípios competitivos de pertença hierárquica: princípio da igualdade e princípio da diferença. Um - o princípio da igualdade opera através de hierarquias entre unidades homogêneas (a hierarquia de estratos socioeconômicos; a hierarquia cidadão/estrangeiro). O outro - o princípio da diferença - opera através da hierarquia entre identidades e diferenças consideradas únicas (a hierarquia entre etnias ou raças, entre sexos, entre religiões, entre orientações sexuais). Os dois princípios não se sobrepõem necessariamente e, por esse motivo, nem todas as igualdades são idênticas e nem todas as diferenças são desiguais. Daí que uma política emancipatória de direitos humanos deva saber distinguir entre a luta pela igualdade e a luta pelo reconhecimento igualitário das diferenças a fim de poder travar ambas as lutas eficazmente (SANTOS, 2010, p. 445-447).

Observa-se que o ponto central sobre a questão da universalidade dos Direitos Humanos em uma perspectiva intercultural é a questão da "dignidade da pessoa humana", pois as várias culturas possuem algum tipo de concepção ou visão acerca da dignidade humana, todos querem viver bem, e mesmo que não usem a terminologia "direitos humanos", algo próximo sempre irão encontrar. Todas as culturas são incompletas e discutíveis nas suas visões de dignidade humana. Nesse sentido faz-se necessário aumentar a consciência de incompletude das culturas para criação de uma visão emancipadora e multicultural dos direitos humanos.

Percebe-se que Boaventura acredita que somente o diálogo entre as diferentes culturas pode ser capaz de mudar a ideia de universalidade dos Direitos Humanos, pois sem a busca de alguns significados comuns como exemplo: Qual é o significado de "dignidade humana" nas demais culturas não ocidentais? Há também necessidade de reconhecer a importância da religiosidade existente das culturas, pois se todas as culturas estão lastreadas nas suas histórias políticas, sociais, lutas, símbolos, signos e significações culturais, que se expressam na religião, nos costumes, na família e na comunidade, não há como iniciar um diálogo e chegar a um denominador comum sem essas considerações.

O caminho para o reconhecimento da universalidade dos direitos humanos é a construção de uma nova roupagem sobre a universalidade de Direitos Humanos através do diálogo intercultural, considerando que toda cultura tem seu aparato jurídico de proteção com as peculiaridades e os valores históricos de povos de uma determinada nacionalidade. O diálogo pode levar ao entendimento que um instituto regional poderá ser complementado através de interessais globais com outros institutos, e vice-versa. 
Ademais, a transformação do modelo atual os direitos humanos proposta por Sousa Santos, parte da verificação de que os direitos humanos não possuem uma fonte ou matriz universal. $\mathrm{O}$ modelo atual dos direitos humanos encontra-se inserido num contexto de construção monocultural ocidental, portanto hegemônico, razão pela qual encontra resistência entre outras culturas.

Nesse sentido, Boaventura (2010, p. 447) traz ainda a ideia de uma política emancipatória dos direitos humanos, no sentido de que uma política emancipatória de direitos humanos deva saber distinguir entre a luta pela igualdade e a luta pelo reconhecimento igualitário das diferenças, a fim de poder travar ambas as lutas eficazmente.

Tal é necessário para que os direitos humanos possam operar como forma de cosmopolitismo, como política emancipatória, e não como globalização ou localismo, de forma contra-hegemônica, e possam ser reconceitualizados como multiculturais. É nessa perspectiva que devem os direitos humanos serem afirmados, na busca da realização da justiça como distribuição, mas também como reconhecimento.

\section{PARA ALÉM DA HERMENÊUTICA: A QUESTÃO MULTICULTURAL}

O diálogo intercultural, ou seja, o diálogo que se estabelece entre as várias culturas do mundo tem como pressuposto o respeito às diferenças e a ausência de qualquer espírito de superioridade de uma cultura em relação à outra. É o que observa Arenhart (2007, p. 81):

\footnotetext{
A atitude intercultural implica o compromisso de valorizar a perspectiva do outro e procurar ser consciente dela, mesmo sem compreendê-la. Essa é uma atitude do filósofo intercultural: conversa com o outro, que representa outro mundo, outro ponto de vista, sendo o outro, em cada caso, uma pessoa viva, fonte de consciência, não uma mente computadorizada. Antes de ser uma relação entre culturas, a interculturalidade é um encontro entre seres humanos.
}

Desta forma, a hermenêutica diatópica é uma proposta de Panikkar e Santos como mecanismo de diálogo intercultural para a formação de um estado transformador. E no diálogo intercultural a troca é de diferentes saberes, de diferentes culturas que consistem em constelações de topoi fortes. Não existem saberes maiores ou menores, o que existem são saberes diferentes, essa é a compreensão que as culturas precisam ter. É a ponderação de Francois Julien (2009, p. 16), no sentido de que o comum das culturas não poderá mais ser 
entendido nem como síntese, tampouco como denominador ou fundamento, mas sim como contínuo desdobramento e guiador por esse universal regulador. :

A hipótese da hermenêutica diatópica traz uma importante ferramenta para o problema da incompletude das culturas. Ainda que a completude não seja um propósito a ser alcançado, diante da sua impossibilidade,o objetivo da hermenêutica diatópica é avultar ao máximo a consciência dessa incompletude através de um diálogo.

Nesse sentido o diálogo intercultural proposto pelo por Panikkar e Sousa Santos através da interpretação da hermenêutica diatópica parece ser um caminho para a universalização dos direitos humanos.

Assim, a interculturalidade é uma discussão acerca da atualização do valor do justo e da justiça dentro de cada cultura, levando em consideração que não se pode discutir sobre um sentido comum e compartilhado de justiça sem perquirir, ou seja, indagar sobre quem o compartilha e o seu cenário.

Por outro lado, no diálogo intercultural, a troca é de diferentes saberes de culturas diversas que equivalem em constelações de topoi fortes. Esses topoi funcionam como proposições de argumentação não questionadas que se tornam controvérsias entre culturas diferentes.

Nesse sentido, vale destacar ainda a ponderação de Chistoph Eberhard (2004, p. 175) ao afirmar que "para um diálogo intercultural produtivo também sobre o direito, não é satisfatório estarmos cientes dos processos e lógicas sociolegais das diferentes culturas; é fundamental que se reconheçam suas específicas visões, horizontes ou universos jurídicos, e seus mitos e símbolos subjacentes".

Boaventura de S. Santos (2014, p. 256) explica que os diferentes universos de sentido, que são cruzados e misturados através do diálogo intercultural, consistem em categorias de topoi fortes. "Os topoi são lugares comuns retóricos mais abrangentes de determinada cultura. Funcionam como premissas de argumentação que, por não se discutirem, dada a sua evidência, tornam possível a produção e a troca de argumentos".

No mesmo sentido, Panikkar observa que os direitos humanos pertencem a um desses lugares comuns a partir do qual interpretamos o universo dos direitos humanos: "Os Direitos Humanos são uma janela através da qual uma cultura determinada concebe uma ordem humana justa para seus indivíduos".

Portanto, não podemos enxergar a outra cultura somente através de nossa janela, pois a outra cultura por sua vez enxerga através de outra janela, necessitamos da ajuda de outra 
cultura, e para isso devemos transformar os diversos portais em uma única janela. O diálogo intercultural traz esse eixo como missão.

Ainda de acordo com Boaventura de S. Santos, é possível ensaiar a hermenêutica diatópica "entre o topos dos Direitos Humanos e o topos de uma cultura islâmica", noção que se refere sempre à comunidade étnica, lingüística ou religiosa de pessoas que são objeto do plano divino de salvação.

E ainda na visão de Panikkar (2004, p. 237), é indispensável que as “culturas nãoocidentais" criem espaço para si próprias e "formulem suas próprias visões homeomórficas correspondentes ou opostas aos 'Direitos' ocidentais"; para se tornar concreto essa condição imprescindível de sua sobrevivência, "é fundamental o papel de uma abordagem filosófica intercultural" .

Por fim, a teoria da hermenêutica diatópica traz uma interessante técnica para a questão da incompletude das culturas. Ainda que a completude não seja um objetivo a ser almejado, diante da sua impossibilidade. O objetivo da hermenêutica diatópica é ampliar ao máximo a consciência dessa incompletude através de um diálogo intercultural.

O diálogo intercultural, a complementação dos topoi da hermenêutica diatópica, proposta pelos autores supramencionados, bem como a introdução de uma plurinacionalidade, são instrumentos encontrados para rechaçar o colonialismo interno, que consiste nos resquícios da herança colonial da América Latina.

A ideia do diálogo intercultural parece utópica assim como os direitos humanos na sua essência Universal o são. Porém, o diálogo ainda parece ser o caminho para a reconstrução da Universalidade dos direitos humanos palpáveis e aceitáveis, considerando que não há como obrigar duas culturas ou mais a alcançar a mesma finalidade ou objetivo se uma delas pretende concretizar apenas sua própria finalidade ou seu próprio objetivo. Lembrando como observa Laura Brito que "a universalidade dos direitos humanos e as diversidades culturais estão em uma relação de mútua implicação em que a mediação é feita pela liberdade".

A convergência destes elementos é que, para Boaventura de Sousa Santos, possibilita um multiculturalismo emancipatório, no qual os direitos humanos passam a ter de fato um caráter contra-hegemônico.

Este é um desafio a ser perseguido com realismo, consciência e vontade humana e política, não obstante as dificuldades para a sua consecução. Diante de tão grande desafio Santos (2010, p. 270) assim conclui: 
Este projecto pode parecer bastante utópico. É certamente, tão utópico quanto o respeito universal pela dignidade humana. E nem por isso este último deixa de ser uma exigência ética. Como disse Sartre, antes de concretizada, uma ideia apresenta uma estranha semelhança com a utopia. Nos tempos que correm o importante é não reduzir a realidade apenas ao que existe.

E certamente o que existe vai além do aparente, do visível, até porque vemos a partir de lentes culturais, o que acaba por gerar miopias culturais, sendo necessário um alargamento de visão a partir das lentes das várias culturas do mundo. Só assim será possível ter uma visão ampliada do mundo, da vida, da existência, uma visão holística que possibilite verdadeiras reconstruções e reconceitualizações dos Direitos Humanos com vistas à sua universalidade.

\section{CONSIDERAÇÕES FINAIS}

Considerando que a ideia hegemônica dos Direitos Humanos posta a partir da Declaração Universal 1948 é uma realidade diante da crise entre as culturas ocidentais e as culturas não ocidentais, faz-se necessário um diálogo intercultural com vistas a uma reconstrução e reconceitualização dos Direitos Humanos.

A ideia hegemônica dos Direitos Humanos a partir da Declaração Universal de 1948 é uma realidade posta, entretanto, tal realidade acaba por se traduzir num choque cultural, mormente no que se refere às culturas ocidentais e orientais, tendo em vista a percepção diversa existente nestas culturas, em razão de seu contexto cultural, dos direitos humanos e da dignidade da pessoa humana, o que exige, para a construção de direitos humanos que se pretendam universais, um diálogo intercultural, tendo em vista que a concepção de direitos humanos que foi erigida a partir da Declaração Universal dos Direitos Humanos é uma expressão do pensamento e da forma de percepção ocidental, desconsiderando valores e percepções de outras culturas.

Os autores Panikkar e Sousa Santos fazem críticas à tese da universalidade dos direitos humanos propalados nas declarações das Revoluções liberal-burguesas e na Declaração Universal dos Direitos Humanos das Nações Unidas, tendo em vista que seu universalismo encontra-se revestido da roupagem do selo do imperialismo ocidental, configurando uma visão central e eurocêntrica de direitos humanos, e que faria parte da marca colonialista das potências ocidentais hegemônicas. Assim, as teorias tradicionais se valeram de uma ideologia na construção da ideia de dignidade humana. 
Inegável que os direitos humanos são direitos essenciais a todos os seres humanos, sem que haja nenhuma discriminação, seja, por raça, cor, gênero, nacionalidade ou qualquer outro motivo, como religião ou política. Eles podem ser civis, políticos e sociais, como o direito à vida, à igualdade perante a lei e à liberdade de expressão. Porém para que os Direitos Humanos sejam de fato universais deve haver diálogo entre as demais culturas que não fizeram parte da construção desses direitos.

Ademais, a garantia dos direitos humanos universais é construída através da lei, podendo citar como exemplo, os tratados e as eis internacionais, portanto, deve haver diálogo entre as culturas para melhor compreensão dos direitos protegidos e ditos como universais. Como pode uma cultura, representada por um estado político, ratificar tratados internacionais de direitos de cuja criação não participou? Porém, o importante é que esses direitos de proteção, sejam nacionais ou sejam internacionais, tenham como eixo a proteção da dignidade humana, também está compreendida a partir de um diálogo intercultural. Logo, o diálogo intercultural proposto por Panikkar e Sousa Santos através da hermenêutica diatópica, do diálogo intercultural e do multiculturalismo emancipatório parece ser um caminho para construção de direitos humanos efetivamente universais.

A hipótese da hermenêutica diatópica traz uma importante ferramenta para o problema da incompletude das culturas. Ainda que a completude não seja um propósito a ser alcançado, diante da sua impossibilidade. O objetivo da hermenêutica diatópica é avultar ao máximo a consciência dessa incompletude através de um diálogo, pois não há como falar em universalidade quando os direitos protegidos são pautados na cultura de minoria, alimentando ainda mais as desigualdades existentes e a exclusão, além da ideia de hierarquia entre as culturas.

A hermenêutica diatópica proposta por Panikkar e também defendida por Sousa Santos como instrumento de compreensão cultural e das diferenças culturais, possibilita as condições para o desenvolvimento de um diálogo intercultural, que por sua vez contribui para o desenvolvimento de um multiculturalismo emancipatório e contra-hegemônico.

Portanto, não faz sentido falar-se em direitos humanos universais sem considerar a questão das identidades, da diversidade cultural, do universo multicultural, pois tal implicaria na imposição de direitos e valores de uma determinada cultura que se pretende superior sobre as demais, descaracterizando a busca pela efetiva universalidade.

A hermenêutica diatópica e o diálogo intercultural contribuem para a formação de uma consciência da riqueza da diversidade cultural, ao invés de se aferrar no monolitismo cultural, 
que estreita a visão de mundo e, por conseguinte, empobrece a compreensão relativa às várias culturas existentes, e que constituem uma grande riqueza da humanidade.

A busca de um caminho de confluência é fundamental para a consecução do objetivo de superação do conflito universalismo/relativismo no que se refere ao alcance e aplicação real dos Direitos Humanos.

Não é razoável e nem possível simplesmente desconsiderar o caminho percorrido até o momento presente na construção dos Direitos Humanos, afirmando que estes não têm nenhuma legitimidade uma vez que são a expressão de uma concepção imperialista e localista de mundo, mas por outro lado, não é possível desconsiderar que a aplicação destes mesmos Direitos Humanos são sim expressão em grande medida da cultura ocidental, além do que sua aplicação segue parâmetros díspares em se referindo a determinadas regiões e culturas do mundo.

Entende-se que o esforço epistemológico realizado por R. Panikkar e Boaventura S. Santos em construir instrumentos heurísticos de análise dos Direitos Humanos em relação a sua dimensão cultural é louvável e contribui significativamente para uma melhor e mais ampla compreensão dos dilemas enfrentados pelos Direitos Humanos no que respeita à diversidade das culturas mundiais, pois constituem como importantes janelas ou lentes que nos possibilitam uma ampliação de visão para a compreensão do problema que envolve o universalismo/relativismo dos direitos humanos, e certamente contribuirão para o enfrentamento desta questão na medida em que sejam considerados no tratamento político e jurídico dos Direitos Humanos.

\section{REFERÊNCIAS BIBLIOGRÁFICAS}

ARENHART, Livio Osvaldo. Pressupostos filosóficos da hermenêutica diatópica proposta por Raimon Panikkar. Revista Direitos Culturais. v. 3, n 3, dezembro de 2007.

BOBBIO, Norberto. A era dos direitos. Rio de Janeiro, Campus, 1992.

BALDI, César Augusto. Direitos Humanos na Sociedade Cosmopolita. Rio de Janeiro: Renovar, 2004.

BRITO, Laura Souza Lima. Liberdade e direitos humanos: fundamentação jusfilosófica de sua universalidade. São Paulo: Saraiva, 2013.

COMPARATO, Fábio Konder. A afirmação histórica dos direitos humanos. 9.ed. São Paulo: Saraiva, 2015. 
EBERHARD, Christoph. Direitos humanos e diálogo intercultural: uma perspectiva antropológica. In BALDI. César Augusto. (Org.). Direitos Humanos na Sociedade Cosmopolita, Rio de Janeiro: Renovar, 2004.

FLORES, Joaquim, Herrera. Direitos Humanos, interculturalidade e racionalidade de resistência. Sequência: estudos jurídicos e políticos, v. 23, n. 44, p. 21, Florianópolis: UFSC, 2002.

JULLIEN, Francois. O Diálogo Entre As Culturas: Do Universal ao multicuturalismo. Rio Janeiro: Jorge Zahar, 2009.

PANIKKAR, Ramon. Religión, Rilosofia y cultura. In: Revista de ciências de las religiones, $\mathrm{n}$. 1, Universidade Complutense, Madri, 1996. Disponível em http://revistas.ucm.es/ccr/11354712/articulos/ILUR9696110125A.PDF. Acesso em 08 de novembro de 2019.

. Fundamentos teóricos para uma perspectiva multicultural. In: BALDI,César Augusto (Org.). Direitos Humanos na Sociedade Cosmopolita. Rio Janeiro: Renovar, 2004.

PIOVESAN, Flávia. Direitos Humanos e o Direito Constitucional Internacional. 7. ed. São Paulo: Saraiva, 2006.

SANTOS, Boaventura de Sousa. Para uma concepção multicultural de Direitos Humanos. In: Contexto Internacional, Rio de Janeiro, vol. 23, n. 1, janeiro/junho 2001, p. 77-34.

- A Gramática do Tempo: para uma nova cultura política. 3. ed. São Paulo: Cortez Editora, 2010.

Direitos Humanos: o desafio da interculturalidade. In: Revista Direitos Humanos, n. 2, julho/2009. Acesso em 08.11.2018.

Se Deus fosse um ativista dos Direitos Humanos. São Paulo: Cortez, 2014

Trabalho recebido em 25 de abril de 2020

Aceito em 07 de maio de 2021 